\title{
Determining equivalent performance for frost durability of concrete containing different amounts of ground granulated blast furnace slag
}

\author{
J. WAWRZEŃCZYK*, T. JUSZCZAK, and A. MOLENDOWSKA
}

Faculty of Civil Engineering and Architecture, Kielce University of Technology, 7 Tysiąclecia Państwa Polskiego Ave., 25-314 Kielce, Poland

\begin{abstract}
This paper deals with the issues pertinent to the design of frost-resistant concretes in exposure class XF3 (high water saturation) when the concretes are made with cements containing ground granulated blast furnace slag (ggbs).The testing programme covered four series of non-air entrained concrete made with cements CEM I, CEM II/A-S, CEM II/B-S and CEM III/A containing 0\%, 13\%, 28\% and 53\% ggbs respectively, and two non-air entrained concrete series with the binder made from CEM I and 0 to $55 \%$ ggbs. The water-binder (w/b) ratio ranged from 0.25 to 0.55 .

Frost durability testing was performed using a modified ASTM C666A procedure to determine changes in mass (dm) and beam length (dL). The relationships occurring between the w/b ratio and ggbs content in the binder and the length change (dL) of the specimens were described using curvilinear regression functions, through the analysis of artificial neural networks.

Slag-content-dependent critical values of the $\mathrm{w} / \mathrm{b}$ ratio were determined taking the length change $\mathrm{dL}=1.3 \mathrm{~mm}$ to be the criterion for the resistance to internal cracking. In the authors' view, this approach can be a good method for checking equivalent performance of concretes made with cements containing mineral additions.
\end{abstract}

Key words: equivalent concrete performance concept ECPC, frost durability, ground granulated blast furnace slag (ggbs).

\section{Introduction}

The requirements for the selection of limiting values for the composition and properties in a particular exposure class for concretes produced from Portland cement CEM I are set in the PN-EN 206 standard [1]. The primary parameter taken into account while designing concrete compositions is the $\mathrm{w} / \mathrm{c}(\mathrm{w} / \mathrm{b})$ ratio [2-4].

According to PN-EN 206, fly ash, silica fume, and ground granulated blast furnace slag can be taken into account in the cement content and water/cement (w/c) ratio, if the suitability of these additions had been established following the $k$-value concept or equivalent performance concepts (equivalent concrete performance concept ECPC, equivalent performance of combinations concept EPCC). More details about these concepts are included in the technical requirements CEN/TR 16639 [5].

The PN-EN 206 standard [1] defines the requirements for concretes exposed to physical corrosion associated with cycles of freezing and thawing (classes XF1-XF4). Guidance on the rules of CEM I-V cements application, depending on the selected exposure class, is given in the Polish standard PNB-6265:2004 [6], a complementary Polish standard to PN-EN 206-1. This standard allows using CEM I, CEM II/A, CEM II/B-S, and CEM III/A and CEM III/B cements (with limits put on ggbs content $-50 \%$ in the case of $32,5 \mathrm{R}$ cement, similarly to the level recommended in the guidelines laid down by ACI Committee 226 [7]) to produce concretes with the required frost durability.

*e-mail: zmsjw@tu.kielce.pl
The standard does not specify the freeze thaw methods for test comparing the equivalent performance of concrete with a given slag cement to that of the reference concrete. Thus, a number of questions have to be answered, e.g. how to design concretes with frost durability taken into account for different exposure classes? How much and what type of cement (slag content, strength class) with what $\mathrm{w} / \mathrm{b}$ ratio should be used to obtain specific properties of the hardened concrete: permeability, absorption, and resistance to chemical attack and frost action? Should the concrete be air-entrained, and if so, in which cases? Which frost-test methods have to be used for the exposure classes XF1-XF4?

The $k$-value concept issues have been presented in numerous research reports, including those of Gruyaert et al. [8], Chromá et al. [9], and Sanjuan et al. [10].

According to CEN/TR 16639, in the Netherlands, the ECPC has been used for the past 15 years for the fly ash/cement combination (CEM I, or CEM I and CEM III), and for the past 10 years for the ground granulated blast furnace slag/cement combination. The procedure, criteria, and test methods used to evaluate the ECPC are set in the Dutch national guidelines CUR-Recommendation 48. For exposure classes XF1 and XF3, only strength tests are required (fcm at 7 days $=20 \mathrm{MPa}$, at 28 days $=33 \mathrm{MPa}$ ). No additional tests have to be performed. For classes XF2 and XF4, frost durability is evaluated using the CDF method with 14 cycles for non-air-entrained concrete.

Harrison [11] claims that the equivalent durability concept will only be available at the national level if and when the national standards body defines a set of reference concretes. For the reference concrete, the recommended w/c value is lower by 0.02 relative to $(\mathrm{w} / \mathrm{c}) \mathrm{max}$ in the particular exposure class. As 
it is unlikely that a selected concrete will give exactly equivalent durability, it is recommended that at least three mixes be cast and tested (mixes of different strength). The results can be used to interpolate the mix proportions that give the suitable (equivalent) durability.

In Belgium, the NBN B15-100 standard has been developed for the practical implementation of the ECPC, which enables the evaluation and attestation of non-standard cement types and/or pozzolanic additions [12]. The evaluation of the durability is based on the results of tests comparing the non-traditional concrete composition with the standard solutions accepted by EN 206-1. Regarding the frost durability test methods, 14 freeze/ thaw cycles, following the European standard EN 1367-1, are recommended. The tensile splitting strength before and after frost testing is considered. The strength reduction of the evaluated concrete should not exceed 1.2 times the strength reduction obtained for the reference concrete.

Linger [13] reports the experience gained from local practices in France, where the ECPC is based on the choice of a reference concrete with better durability properties than a concrete strictly complying with the minimum requirements of EN 206-1 (with the same aggregate used). The reference concrete should meet the following criteria:

- w/b ratio reduced by 0.05 in comparison with the limiting value for the particular exposure class,

- equivalent binder content increased by $5 \%$ compared to $\mathrm{C}_{\min }$ prescribed by EN $206-1$, or a $0.5 \%$ decrease in water absorption coefficient.

The equivalent performance concept in exposure class XF1 is based on the concrete water porosity $\varepsilon$ (absorption under vacuum), determined relative to the concrete paste volume fraction, or the concrete water absorption $\alpha$ to the total concrete volume.

For exposure classes XF3 and XF4, the test methods are specified in the French standard NF P 18-424 (Concrete-freeze test on hardened concrete - freeze in water/thaw in water), XP P 18-425 (Concrete-freeze test on hardened concrete - freeze in air/thaw in water), XP P 18-420 (Concrete-scaling test for hardened concrete surfaces exposed to frost in the presence of a salt solution). These tests can be applied directly to the candidate concrete, without a comparison to the reference concrete.

No procedure is specified for the XF2 exposure class, and thus, various situations are considered: when a highly saturated concrete is exposed to de-icing salt solutions, the tests prescribed for XF4 can be applied; in the case of other concretes (e.g. vertical elements), the protocol proposed for XF3 can be used.

According to Harrison [11], in some CEN member countries there is no need for an equivalent durability concept for XF exposure classes.

Experience gained so far from the application of the technical specification TS 12390-9 has in some countries raised concerns that the tests are too strict and lead to situations where certain concretes have negative results in laboratory frost-durability tests, whereas the same concretes in the structure turn out to remain durable after many years in real service conditions. A less severe test is thus proposed to give a better correlation with in situ observations.
Richardson et al. [14] presented some experience to date from Irish, Canadian, and French studies on the durability performance of concretes manufactured with a binder composed of limestone cement and ground granulated blast furnace slag (ggbs). Satisfactory performance is demonstrated by comparative reference to benchmark concretes. The authors therefore reflect on the potential use of ECPC methodologies in helping to promote the use of national standards as positive influencers of change.

In Poland, any equivalent concrete performance concept ECPC is not used or considered. The PN-EN 206 standard redirects those interested to CEN/TR 16639 for details [5].

A number of research reports are available in the literature concerning frost durability of concretes containing ggbs. Among the authors who have addressed this issue, there are: Deja [15], Giergiczny, Glinicki et al. [16], Stark et al. [17], and Rusin et al. [18].

The results of the study conducted by the authors of this paper provide an input to the debate over the guidelines for the design of frost-resistant, non-air-entrained concretes with binders (cements) having a varying content of ggbs. The focus is on the XF3 exposure class, in which the concrete in elements of structures can exhibit high water saturation, and which are exposed to cycles of freezing and thawing. For this exposure class, the standard [1] prescribes the $\mathrm{w} / \mathrm{c}$ ratio to be equal to or less than 0.50 , and recommends the use of air entrainment. If the air entrainment is not used, adequate performance (frost durability) test methods are recommended, which compare the results to those of a concrete with a confirmed freeze/thaw resistance in the dedicated exposure class. This is the essence of the equivalent concrete performance concept.

\section{Description of the tests}

The tests were aimed at determining the effect of various amounts of ggbs in the binder on the internal frost durability of concretes exposed to high water saturation without de-icing agents (XF3 exposure class). Another objective of the tests was to find the relationships between the strength, absorption, permeability, and frost durability in concretes produced with a variety of $\mathrm{w} / \mathrm{b}$ ratios, ranging from 0.25 to 0.55 .

The experiment programme included manufacturing:

- four series of non-air-entrained concrete made with CEM I, CEM II/A-S, CEM II/B-S, and CEM III/A, with ggbs contents of $0 \%, 13 \%, 28 \%$ and $53 \%$, respectively,

- two series of non-air-entrained concrete with the binder made of CEM I and the addition of ggbs ranging from 0 to $55 \%$.

The following materials were used in the tests:

- cements CEM I 42,5R HSR/NA, CEM II/A-S 42,5N, CEM II/B-S 32,5R, CEM III/A 32,5N LH/HSR/NA, CEM I 42,5R NA,

- an addition of ground granulated blast furnace slag (ggbs),

- natural sand $0 / 2 \mathrm{~mm}$,

- coarse basalt aggregate, fractions 4/8 and 8/16 mm,

- plasticizer. 
The aggregate sizes in gradation were selected in the following proportion $\mathrm{P}: \mathrm{B}_{4-8}: \mathrm{B}_{8-16}=32 \%: 33 \%: 35 \%$. Standard properties of the cements and slag (ggbs), specified in accordance with EN standards, are listed in Table 1.

Table 1

Basic properties of cements and blast furnace slag (ggbs)

\begin{tabular}{c|c|c|c|c|c|c}
\hline & Series & $\begin{array}{c}\text { ggbs } \\
\%\end{array}$ & $\begin{array}{c}\text { gc g/ } \\
\mathrm{cm}^{3}\end{array}$ & $\begin{array}{c}\text { Blaine } \\
\mathrm{cm}^{2} / \mathrm{g}\end{array}$ & \multicolumn{2}{|c}{$\begin{array}{c}\text { Compressive } \\
\text { strength, MPa }\end{array}$} \\
\cline { 5 - 7 } & & $\mathbf{2}$ days & $\mathbf{2 8}$ days \\
\hline $\begin{array}{c}\text { CEM I 42,5R } \\
\text { HSR/NA }\end{array}$ & $\mathrm{C} 1$ & 0 & 3.14 & 3421 & 18.2 & 44.2 \\
\hline $\begin{array}{c}\text { CEM II/A-S } \\
42,5 N\end{array}$ & $\mathrm{C} 2$ & 13 & 3.04 & 3547 & 27.4 & 56.1 \\
\hline $\begin{array}{c}\text { CEM II/B-S } \\
32,5 \mathrm{R}\end{array}$ & $\mathrm{C} 3$ & 28 & 3.02 & 3700 & 23.6 & 55.9 \\
\hline $\begin{array}{c}\text { CEM } \\
\text { III/A 32,5N } \\
\text { LH/HSR/NA }\end{array}$ & $\mathrm{C} 4$ & 53 & 2.96 & 4113 & - & 45.2 \\
\hline $\begin{array}{c}\text { CEM I } \\
42,5 \mathrm{R} N A\end{array}$ & $\mathrm{C} 5$ & 0 & 3.15 & 3181 & 22.1 & 54.1 \\
\hline \begin{tabular}{c} 
ggbs \\
\hline
\end{tabular} & - & - & 2.88 & 4445 & - & - \\
\hline
\end{tabular}

The concrete mix was tested for consistency using the concrete slump test, in accordance with PN-EN 12350. A plasticizer was used to provide stable consistency S3. While pouring the concrete into the moulds, metal gauge studs were fixed on the front faces of the beam specimens intended for frost durability testing. These gauge studs enabled the measurement of linear length change.

Table 2 summarizes the basic information about the composition and properties of the concrete mixes.

\section{Test methods}

The specimens were demoulded after 24 hours and were stored in water (temp. $20 \pm 2^{\circ} \mathrm{C}$ ) for up to 7 days, and then in air (temp. $20 \pm 2^{\circ} \mathrm{C}, \mathrm{RH}=65 \pm 5 \%$ ) for 21 days. The compressive strength of the concrete was determined for each series on three specimens with $100 \mathrm{~mm}$ sides after 28 days of curing (PN-EN 12390-3:2011). A water absorption test was carried out on cubes with $100 \mathrm{~mm}$ sides - three cubic specimens for each concrete series (Polish standard PN-88/B-06250). Permeability Q was studied on three concrete cores, $94 \mathrm{~mm}$ in diameter and $50 \mathrm{~mm}$ in height, using a rapid chloride permeability test (RCPT), following the ASTM C 1202 procedure [19]. The method involves the measurement of electrical current of a pre-set voltage $(60 \mathrm{~V})$ as a function of time, flowing through a concrete specimen being tested. The value of the electrical current is read every 5 minutes. The test took 6 hours to complete, and the results were expressed in coulombs.
Table 2

Basic information on the composition of the concrete mixes

\begin{tabular}{|c|c|c|c|c|}
\hline Series & W/B & $\begin{array}{l}\text { Binder } \\
\mathrm{kg} / \mathrm{m}^{3}\end{array}$ & $\begin{array}{c}\text { ggbs } \\
\% \text { m.c. }\end{array}$ & $\begin{array}{c}\text { Aggregate } \\
\mathrm{kg} / \mathrm{m}^{3}\end{array}$ \\
\hline $\mathrm{C} 1-1$ & 0.25 & 609 & 0 & 1861 \\
\hline $\mathrm{C} 1-2$ & 0.35 & 463 & 0 & 1990 \\
\hline $\mathrm{C} 1-3$ & 0.45 & 366 & 0 & 2060 \\
\hline $\mathrm{C} 1-4$ & 0.55 & 325 & 0 & 2052 \\
\hline C2-1 & 0.25 & 602 & 13 & 1840 \\
\hline $\mathrm{C} 2-2$ & 0.35 & 458 & 13 & 1970 \\
\hline $\mathrm{C} 2-3$ & 0.45 & 369 & 13 & 2058 \\
\hline $\mathrm{C} 2-4$ & 0.55 & 324 & 13 & 2053 \\
\hline C3-1 & 0.25 & 604 & 28 & 1842 \\
\hline C3-2 & 0.35 & 460 & 28 & 1976 \\
\hline C3-3 & 0.45 & 365 & 28 & 2051 \\
\hline C3-4 & 0.55 & 324 & 28 & 2046 \\
\hline C4-1 & 0.25 & 600 & 53 & 1830 \\
\hline $\mathrm{C} 4-2$ & 0.35 & 458 & 53 & 1968 \\
\hline C4-3 & 0.45 & 365 & 53 & 2051 \\
\hline C4-4 & 0.55 & 327 & 53 & 2061 \\
\hline C5-1 & 0.42 & 359 & 0 & 2089 \\
\hline $\mathrm{C} 5-2$ & 0.42 & 353 & 15 & 2040 \\
\hline C5-3 & 0.42 & 353 & 35 & 2038 \\
\hline C5-4 & 0.42 & 355 & 55 & 2052 \\
\hline C6-1 & 0.45 & 364 & 0 & 2028 \\
\hline C6-2 & 0.45 & 365 & 20 & 2042 \\
\hline C6-3 & 0.45 & 366 & 40 & 2039 \\
\hline C6-4 & 0.45 & 367 & 60 & 2024 \\
\hline
\end{tabular}

The resistance to cycles of freezing and thawing was determined on two $80 \times 80 \times 350 \mathrm{~mm}$ beams, according to a modified ASTM C666 A method. The ASTM C666 A method is considered to be severe, as before and during the freezing the specimens are subjected to maximum water saturation. The introduced modification consisted of curing the specimens in water for 7 days and then in air for 21 days, which allowed them to dry. After 28 days of curing, the beam specimens were soaked in water for 7 days and then kept at all times in a metal container with water, for repeated freeze/thaw cycles (high water saturation without de-icing agents - XF3 exposure class, in accordance with PN-EN 206). The specimens were exposed to 300 freeze/thaw cycles at temperatures ranging from $+10 \pm 2^{\circ} \mathrm{C}$ to $-18 \pm 2{ }^{\circ} \mathrm{C}$, with 3 cycles per day. Once a week, the specimens were removed from the freezing chamber and the level of degradation was recorded, based on the visual observations and the measurements changes in mass $(\mathrm{dm})$ and length $(\mathrm{dL})$ of the beam specimens. 


\section{Results and analysis of the tests}

Table 3 summarizes the results of the tests for the properties of hardened concrete. The matrix diagram in Fig. 1 shows the relationships among the constituents and the properties of the hardened concrete. In the top-right corner of the figure, there is a table containing partial correlation coefficients that occur between the factors.

Table 3

Results for absorption $\mathrm{n}_{\mathrm{w}}$, compressive strength $\mathrm{f}_{\mathrm{cm}}$, permeability $\mathrm{Q}$, loss of mass $\mathrm{dm}$ and length change $\mathrm{dL}$ of the beams under freezing conditions

\begin{tabular}{c|c|c|c|c|c}
\hline Series & \multirow{2}{*}{$\mathbf{n}_{\mathbf{w}}$} & Q RCPT & $\mathbf{f}_{\mathbf{c m}}$ & \multicolumn{2}{|c}{ Frost durability } \\
\cline { 5 - 6 } & $\mathbf{\%}$ & Coulombs & $\mathbf{M P a}$ & $\mathbf{d m}$ & $\mathbf{d L}$ \\
\hline $\mathrm{C} 1-1$ & 2.80 & 867 & 114.8 & -8.0 & 0.01 \\
\hline $\mathrm{C} 1-2$ & 3.00 & 1181 & 85.0 & -6.0 & -0.02 \\
\hline $\mathrm{C} 1-3$ & 3.60 & 1689 & 83.9 & -11.0 & 0,90 \\
\hline $\mathrm{C} 1-4$ & 4.80 & 2502 & 68.3 & -225.0 & 1.60 \\
\hline $\mathrm{C} 2-1$ & 2.60 & 787 & 108.0 & 0.0 & -0.14 \\
\hline $\mathrm{C} 2-2$ & 3.30 & 1083 & 97.1 & 3.0 & 0.00 \\
\hline $\mathrm{C} 2-3$ & 3.50 & 1206 & 84.5 & 19.0 & 0.70 \\
\hline
\end{tabular}

\begin{tabular}{c|c|c|c|c|c}
\hline Series & \multirow{2}{*}{$\mathbf{n}_{\mathbf{w}}$} & Q RCPT & $\mathbf{f}_{\mathbf{c m}}$ & \multicolumn{2}{|c}{ Frost durability } \\
\cline { 5 - 6 } & $\mathbf{\%}$ & Coulombs & $\mathbf{M P a}$ & $\mathbf{d m}$ & $\mathbf{d L}$ \\
\hline C2-4 & 4.80 & 1550 & 64.9 & -215.0 & 2.68 \\
\hline C3-1 & 2.70 & 429 & 109.1 & -3.0 & 0.00 \\
\hline C3-2 & 3.20 & 792 & 101.4 & 3.0 & -0.04 \\
\hline C3-3 & 3.60 & 991 & 84.9 & 21.0 & 1.12 \\
\hline C3-4 & 4.50 & 1226 & 70.2 & -50.0 & 2.68 \\
\hline C4-1 & 2.40 & 364 & 110.9 & -5.0 & 0.03 \\
\hline C4-2 & 3.40 & 600 & 85.2 & -2.0 & 0.40 \\
\hline C4-3 & 4.10 & 645 & 62.8 & -262.0 & 2.56 \\
\hline C4-4 & 4.90 & 894 & 56.7 & -556.0 & 4.83 \\
\hline C5-1 & 4.00 & 2467 & 73.2 & -117 & 0.14 \\
\hline C5-2 & 3.71 & 2869 & 74.7 & -117 & 0.35 \\
\hline C5-3 & 3.97 & 1269 & 68.9 & -238 & 0.84 \\
\hline C5-4 & 3.84 & 790 & 60.4 & -160 & 1.10 \\
\hline C6-1 & 4.23 & 2631 & 72.8 & 3.4 & 0.59 \\
\hline C6-2 & 4.24 & 2108 & 65.2 & -219.7 & 0.99 \\
\hline C6-3 & 4.22 & 1558 & 68.9 & -259.8 & 1.79 \\
\hline C6-4 & 4.15 & 1338 & 60.9 & -151.7 & 2.56 \\
\hline
\end{tabular}
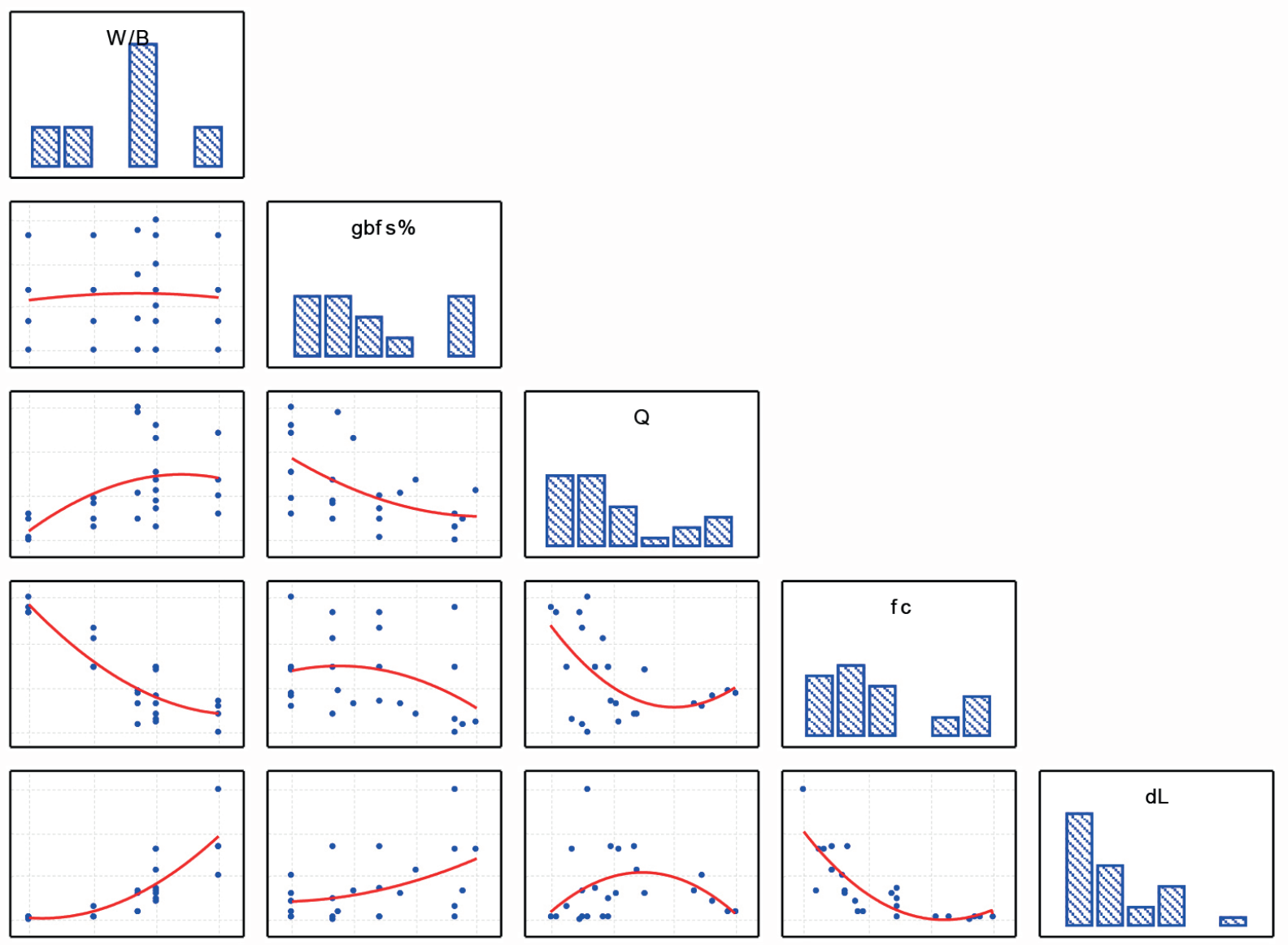

Fig. 1. Relationships between the parameters 


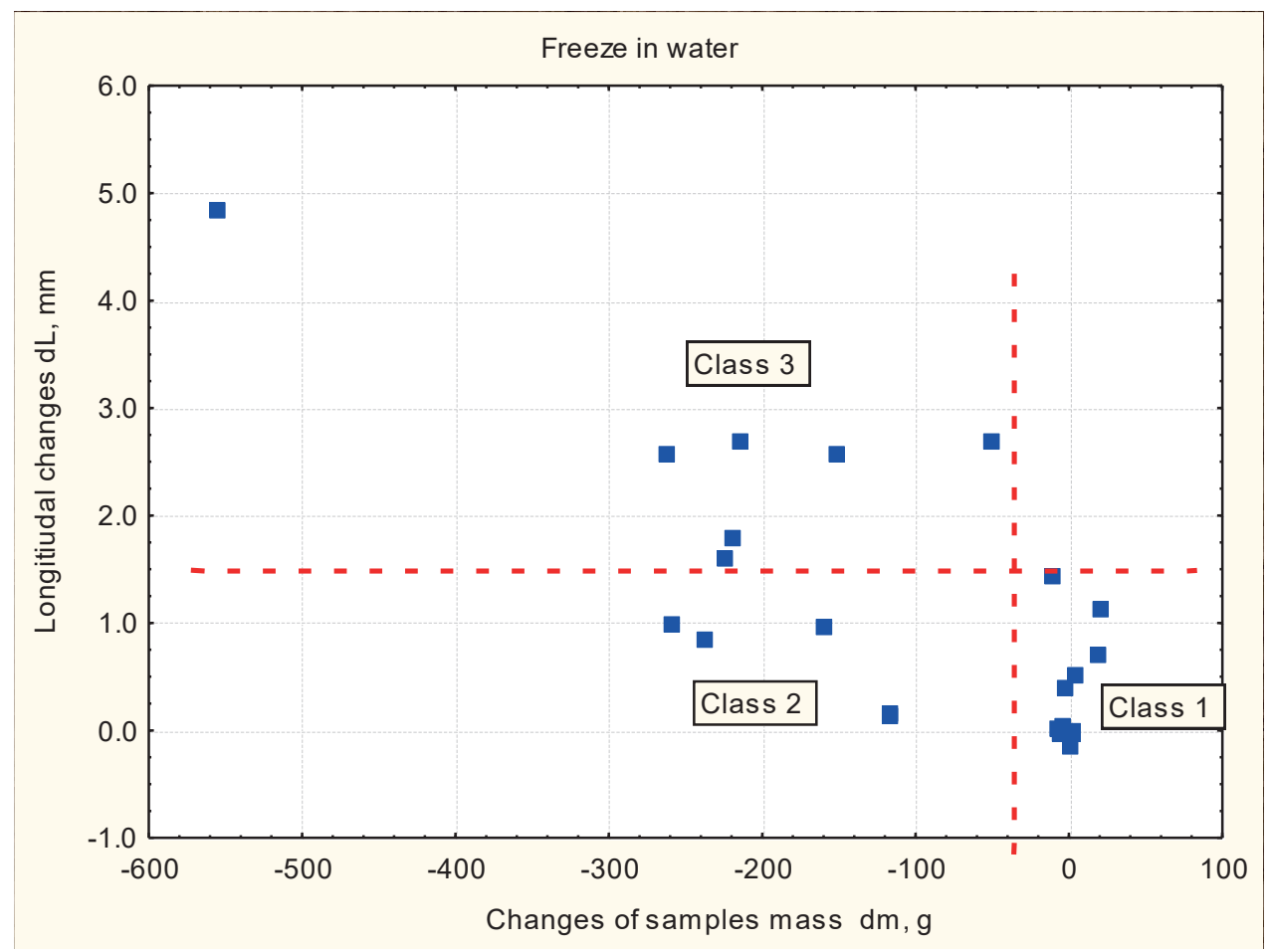

Fig. 2. Relationship between the loss of mass $(\mathrm{dm})$ and length change $(\mathrm{dL})$ against concrete frost-durability classes

Close relationships (non-linear) between the w/b ratio, compressive strength $\mathrm{f}_{\mathrm{c}}$, and linear expansion $\mathrm{dL}$ are evident.

Fig. 2 shows the results of the frost durability tests (variations in mass $\mathrm{dm}$ and length $\mathrm{dL}$ for each series of concrete specimens). Two lines divide the area of the graph into subareas (limiting values: $\mathrm{dm}=50 \mathrm{~g}$ and $\mathrm{dL}=1.3 \mathrm{~mm}$ ) with three frost durability classes for concrete: class 1 - concretes of the highest frost durability, for which minor changes in mass $(\mathrm{dm})$ and length $(\mathrm{dL})$ were recorded; class 2 - concretes for which minor changes in length $(\mathrm{dL})$ and considerable mass loss (dm) (scaling) were recorded; class 3 - concretes with the lowest frost durability, with considerable mass loss (dm) and length change $(\mathrm{dL})$. The length change of the specimens, recorded after 300 cycles of freezing and thawing, was assumed to be the basis for concluding the extent of deterioration in the concrete.

Class 1 - high resistance to cycles of freezing and thawing - includes the concretes with high compressive strength $\mathrm{f}_{\mathrm{cm}}>70 \mathrm{MPa}(\mathrm{w} / \mathrm{b}$ ratio $\leq 0.35)$ and tight structure: absorption $\mathrm{nw}=2.4-3.6 \%$ and permeability $\mathrm{Q}<1100$ coulombs. Concretes in class 3 are not frost-resistant, with the absorption value of nw $>4 \%$. Class 2 includes the concretes that are resistant to internal damage, but non-resistant to surface scaling, with absorption ranging from $3.7 \%$ to $4.3 \%$.

The influence of the $\mathrm{w} / \mathrm{b}$ ratio and the content of ggbs on the length change of the specimens after 300 cycles of freezing and thawing was described using a nonlinear regression function in the form of an artificial neural network $A N N-\mathrm{dL}=\mathrm{f}\{\mathrm{w} / \mathrm{b}$, ggbs\%, Q \}. This approach allows the generalisation of the results. The artificial neural network used had 3 layers in a [3-4-1] design: three inputs, four nodes in the hidden layer, and one output (Fig. 3). Calculations were made with an ANN computer programme QNET'97 using the back-propagation method. For the analysed data set $\mathrm{N}=24$, the RMS error was 0.0218 and the correlation coefficient was $\mathrm{R}=0.992$. Fig. 4 shows the comparison of the measured dL with the ANN-dL results.

The ANN-dL model was used to analyse the effect of the ggbs content in the binder and the of the w/b ratio on frost durability. To use the model, it is necessary to enter a $\mathrm{Q}$ value, which is also dependent on these factors. The $\mathrm{Q}$ value is estimated

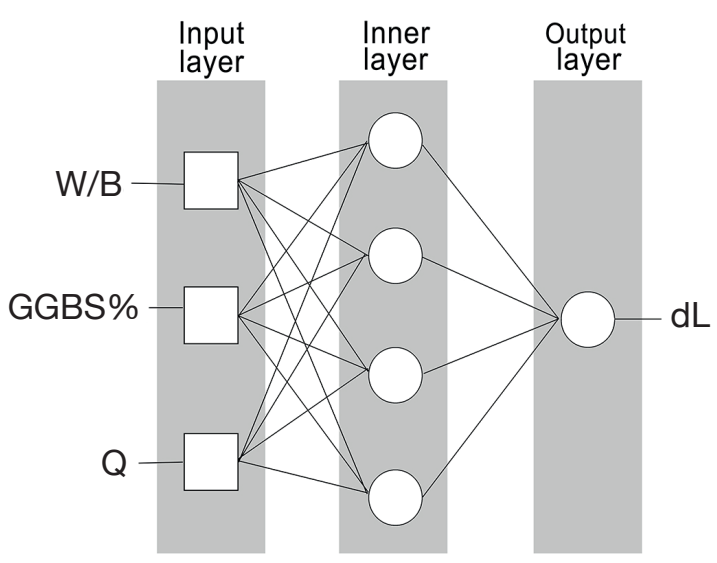

Fig. 3. Schematic diagram of the ANN-dL [3-4-1] architecture 


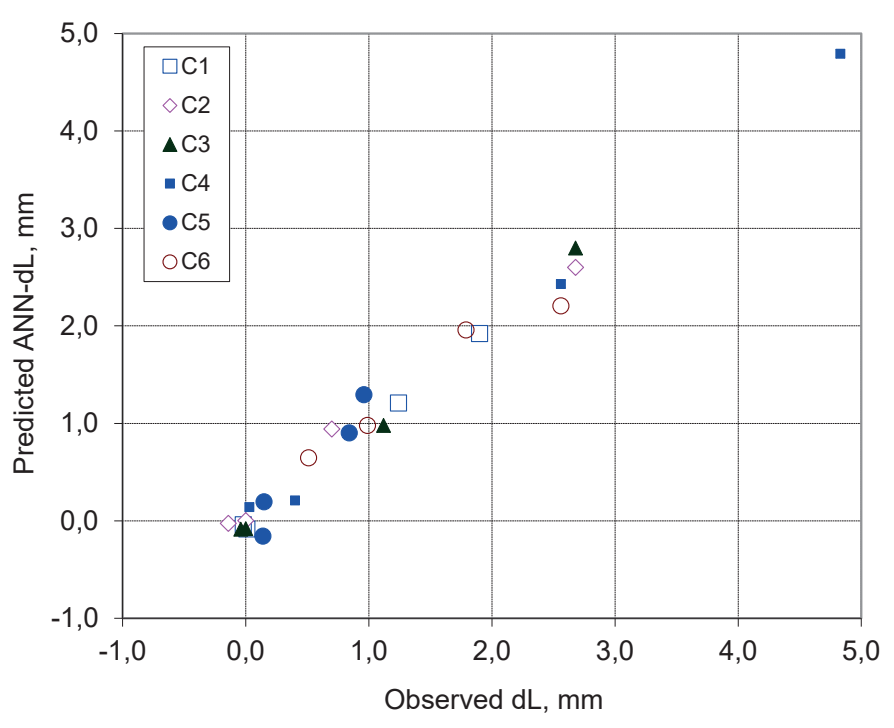

Fig. 4. Calculation results obtained using the ANN-dL model

based on the regression-type relationship presented in Fig. 5. For those parameters, the effect of the changes in $\mathrm{dL}$ on the $\mathrm{w} / \mathrm{b}$ ratio and ggbs content was determined, as shown in Fig. 6. The

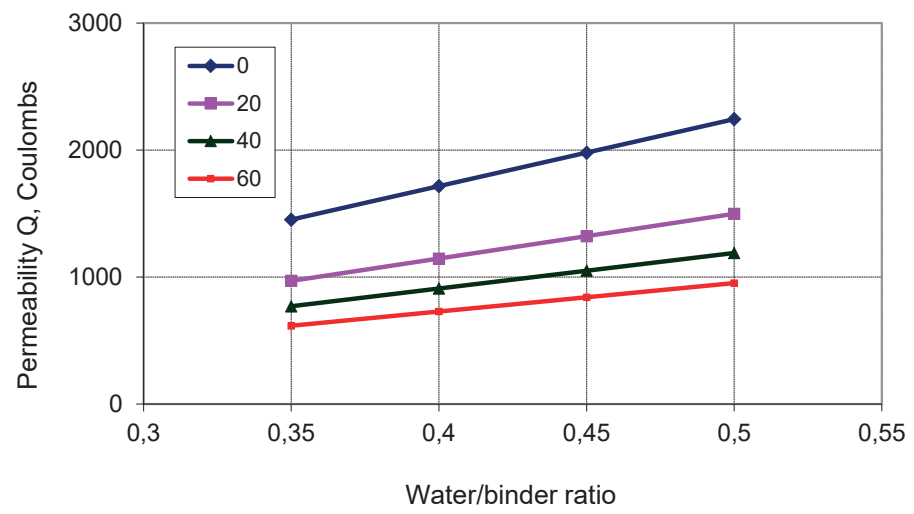

Fig. 5. Relationships between permeability $\mathrm{Q}$ and w/b ratio and ggbs content taken for calculations

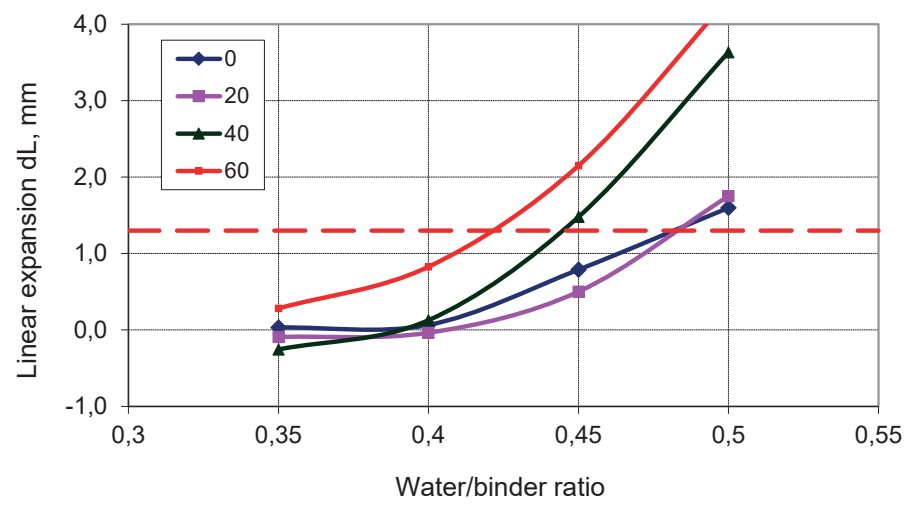

Fig. 6. The influence of of $\mathrm{w} / \mathrm{b}$ ratio and ggbs content on the length change of samples, $\mathrm{dL}$ resistance of concrete to internal degradation increases with the decreasing value of the $\mathrm{w} / \mathrm{b}$ ratio. A $20-30 \%$ ggbs content in the binder does not affect frost durability. A ggbs content increased to $40-60 \%$ has a clear negative effect on the frost durability. At the given w/b ratio, the increase in ggbs content results in a larger extent of damages in concrete.

With $\mathrm{dL}_{\mathrm{kr}}=1.3 \mathrm{~mm}$ as the frost durability criterion, the critical value of the $\mathrm{w} / \mathrm{b}$ ratio $(\mathrm{w} / \mathrm{b})_{\mathrm{cr}}$ can be determined for the cement containing the given amount of ggbs.

\begin{tabular}{ccccc}
\hline ggbs, \% & $\mathbf{0}$ & $\mathbf{2 0}$ & $\mathbf{4 0}$ & $\mathbf{6 0}$ \\
\hline$(\mathrm{W} / \mathrm{B})_{\mathrm{cr}}$ & 0.48 & 0.48 & 0.44 & 0.42 \\
\hline
\end{tabular}

While for the Portland cement CEM I or a small content of ggbs the critical value of $\mathrm{w} / \mathrm{b}$ ratio will be about 0.48 , for a cement with $40 \%$ ggbs content the value of $(\mathrm{w} / \mathrm{b})_{\mathrm{kr}}$ will be 0.44 , and 0.42 for a $60 \%$ content of ggbs. The reduction in the $\mathrm{w} / \mathrm{b}$ ratio is directly associated with higher strength (class) of concrete.

In the view of the authors of this paper, the analysis of how the type of slag cement affects the resistance of concrete to internal damage based on the measurement of the specimen critical strain can be a good method for checking the equivalent performance (frost durability) of a concrete containing that particular cement.

\section{Conclusions}

The following conclusions were drawn from the analysis of the test results for several series of concretes with the $\mathrm{w} / \mathrm{b}$ ratio ranging from 0.25 to 0.55 , made with binders containing varying amounts of ground granulated blast furnace slag:

- On the basis of the frost resistance tests, with the limiting values $\mathrm{dm}=50 \mathrm{~g}$ and $\mathrm{dL}=1.3 \mathrm{~mm}$, three classes of concrete frost durability were established, defining the concrete degradation mode: class 1 - concretes with the highest level of frost resistance, for which minor changes in mass (dm) and minor length change dL were recorded; class 2 - concretes for which minor length change $\mathrm{dL}$ was recorded, but mass loss $(\mathrm{dm})$ was considerable; class 3 - concretes with the lowest frost durability, where both mass loss and length change were significant.

- The increase in ggbs content in the binder results in worse frost durability levels in exposure class XF3 - regarding both mass loss and length change of the concrete specimens.

- The effect of length change (dL) as an internal damage indicator of the $w / b$ ratio and ggbs content was described using a simple ANN-dL model. Analysis of the relationship obtained against the adopted criterion $\mathrm{dL}=1.3 \mathrm{~mm}$ allowed to determine critical values of the $\mathrm{w} / \mathrm{b}$ ratio, in relation to the ggbs content. While for the binder containing a small amount of ggbs (smaller than 20-30\%), the critical w/b ratio was 0.48 , and when the ggbs content was increased to $40-60 \%$, the critical $\mathrm{w} / \mathrm{b}$ ratio was lower, reaching the value of $0.42-0.44$. 
- In the opinion of the authors, the approach presented in this paper allows for relatively easy determination of equivalent performance (frost durability) of concretes made of cements containing mineral additives.

- Further study is necessary to verify the obtained relationships of cements with ggbs derived from other sources and different strength classes.

Acknowledgements. The research project was provided under the POIG 01.01.02-10-106/09 project, "Innovative measures and efficient methods for the improvement of safety and durability of buildings and transportation infrastructure in the strategy of sustainable development".

\section{REFERENCES}

[1] "Specification, performance, production and conformity", PN-EN 206 Concrete.

[2] I. Hager, "Behaviour of cement concrete at high temperature", Bull. Pol. Ac.: Tech 61 (1), 145-154 (2013).

[3] T. Zdeb, "Ultra-high performance concrete - properties and technology", Bull. Pol. Ac.: Tech 61 (1), 183-193 (2013).

[4] L. Czarnecki and P. Woyciechowski, "Prediction of the reinforced concrete structure durability under the risk of carbonation and chloride aggression”, Bull. Pol. Ac.: Tech 61 (1), 173-181 (2013).

[5] CEN/TR 16639, "Use of k-value concept, equivalent concrete performance concept and equivalent performance of combinations concept".

[6] "Specification, performance, production and conformity", PN-B-06265 Polish National Supplements: PN-EN 206-1:2003 Concrete.

[7] ACI committee 226: Ground granulated blast furnace slag as a cementitious constituent in concrete. ACI Material Journal 84 (4), 327-342 (1987).

[8] E. Gruyaert, M. Maes, and N. De Belie, "Performance of BFS concrete: k-value concept versus equivalent performance concept”, Construction and Building Materials 47, 441-455 (2013).
[9] M. Chromá, P. Rovnaniková, B. Teplý, K. Bergmeister, and A. Strauss, "Concrete durability and the k-value concept", $\mathrm{Ce}$ ment Lime Concrete 2, 81-92 (2014).

[10] M.A. Sanjuan, A. Pineiro, and O. Rodriguez, "Ground granulated blast furnace slag efficiency coefficient (k value) in concrete. Applications and limits", Materiales de Construcción 61 (302), 303-313 (2011).

[11] T.A. Harrison, "Equivalent durability concept", Nordic Exposure sites - input to revision of EN 206-1. Workshop proceeding 8, Hirtshals, Denmark, (2008).

[12] G. De Schutter, "Belgian implementation of the ECPC-concept following EN 206-1", XII DBMC International Conference on Durability of Building Materials and Components, Porto, Portugal, (2011).

[13] L. Linger, E. Roziere, A. Loukili, F. Cussigh, and P. Rougeau, "Concrete equivalent performance concept for durability - an operational guide for the comparative approach", Proceedings of The Fourth International Congress, Mumbai, India, 540-547 (2014).

[14] M.G. Richardson, C. McNally, M. O'Connell, and P. Seymour, "Equivalent concrete performance concept: Durability studies of limestone cement/GGBS concretes", 3rd International Conference on the Durability of Concrete Structures, Queen's University, Belfast, Northern Ireland, (2012).

[15] J. Deja, "Freezing and de-icing salt resistance of blast furnace slag concrete", Cement Concrete Composites 25, 357-361 (2003).

[16] Z. Giergiczny, M.A. Glinicki, M. Sokołowski, and M. Zielinski, "Air void system and frost-salt scaling of concrete containing slag-blended cement", Construction and Building Materials 23, 2451-2456 (2009).

[17] J. Stark, and H. Ludwig, "Freeze-thaw and freeze-deicing salt resistance of concretes containing cement rich in granulated blast furnace slag", ACI Materials Journal 94 (1), 47-55 (1997).

[18] Z. Rusin and P. Świercz, "Volumetric strains of cement-based mortars caused by ice formation in terms of frost resistance diagnostics", Bull. Pol. Ac.: Tech 63 (1), 35-41 (2015).

[19] "Standard test method for electrical indication of concrete's ability to resist chloride ion penetration", ASTM C1202 - 12 . 